of Science by hand cost scientific men $\$ 10,000$ per year. Of course it might if men sat down and opened the magazine and then afterwards read it through, but I have always found that I got more out of an unopened magazine than an opened one, because I would more carefully examine a magazine that $I$ had to open than one that was opened; because, as I opened it, I either read the magazine, or if I didn't want to read the articles, got a rough idea of them as I opened the magazine, and for that reason whenever possible I try to get an unopened magazine.

We are losing in this nonsense regarding effciency a good deal of the human interest in men in our employ and it's a great question to my mind if efficiency is not doing more damage than good.

H. $\mathrm{P}$.

[The editor shares to a certain extent his correspondent's prejudice against trimmed magazines and efficiency experts. An untrimmed journal looks as if it were waiting for careful reading and the binder; a trimmed one for a hasty glance and the waste-paper basket. This, however, is a matter of association, which is already changing with general usage. Trimmed magazines and efficiency experts have apparently arrived. We must get used to the one and treat the other with discretion.]

\section{SCIENTIFIC BOOKS}

Die Kultur der Gegenwart. Herausgegeben von Paul Hinneberg. Teil III., Abtlg. III. Physik, S762. Teubner, 1915.

During the past two years much has been written about Kultur. There has been a tendency in the English-speaking world to identify it with "culture," a term which with us is variously defined. While our dictionaries may give as the equivalents of culture the following: knowledge, development, the training of the mind, the intellectual side of civilization - the more common use of the English word is associated with refinement, taste, manners. It is this common meaning which leads Stephen Leacock to speak of a cultured man as "one who has acquired a silk hat and the habit of sleeping in pyjamas." Associating culture with refinement we generally think of it as denoting knowledge of fine arts, of music, literature, languages, especially ancient languages. Indeed, John Bright complained that the only necessary qualification of a cultured man was that he possess a smattering of two dead languages, Latin and Greek. Gradually, however, we are getting away from identifying culture with a knowledge chiefly of languages, living, dead and half dead, with taste and manners, and are coming to view it as "that complex whole which includes knowledge, belief, art, morals, law, custom and any other capabilities and habits acquired by man as a member of society." In this view we are approaching the idea of "Kultur" as set forth in this volume and its companions in the series. In passing it should be noted that even among Germans there are a variety of views concerning "Kultur." Professor Münsterberg defines it as "the consciousness of nationalism, the subordination of the individual to the national ideal." But if one desires to ascertain the meaning of "Kultur" as here set forth, one should read the 760 pages of this volume which is concerned only with physics. One then should survey the contents of the other fifty-seven volumes of the "Kultur" series.

The fifty-eight volumes comprising "Die Kulture der Gegenwart" are divided as follows: fourteen are devoted to religion, philosophy, literature, music, art; ten to history, economics, the political and social sciences; nineteen to mathematical, natural and medical sciences; fifteen to technical sciences.

In the volume under review there is presented the philosophical evolution rather than the history of physics. Ideas are traced from their origin to their present fullness. One is thus able to observe how the contributions of the succeeding centuries and decades compare with one another. It is interesting to note that in the article on mechanics, which may be regarded as the oldest portion of physics, thirty-six pages suffice to bring the subject to near the end of the nineteenth century and twenty-five pages are given to the development during the past generation. In the other thirty-five articles thirteen are almost en- 
tirely concerned with the developments of the past twenty-five years and the other articles are largely taken up with such development. Obviously physics is a new subject and Kultur has grown in recent years.

The thirty-six articles in this volume are contributed by thirty-two specialists, all Germans with two exceptions-H. A. Lorentz and $P$. Zeeman. The assignment of subjects to writers is, with perhaps a couple of exceptions, that which an American physicist would make. Thus H. Rubens writes on Wärmestrahlung; W. Wein on Theorie der Wärmestrahlung; Dorn on Experimental Atomistik; Einstein on Theoretische Atomistik and Die Relativitätstheorie; Lorentz on Die Maxwellsche Theorie and Die elektronen Theorie; P. Zeeman on Magnetooptik; Lecher on Die Entdeckungen von Maxwell und Hertz; Braun on Die Drahtlose Telegraphie; Kaufmann on Die Kathodenstrahlen und Die Röntgenstrahlen; Max Planck on Das Prinzip der kleinsten Wirkung und Verhältniz der Theorie zueinander. We are rather surprised to see that the article on Die Positiven Strahlen is given by Gehrcke and Reichenheim rather than by Starke. To the latter is assigned Das Elektrische Leitungsvermögen. A detailed and technical review of this large work is here impossible, but certain general characteristics may be noted.

The authors treat their respective topics in a general and philosophic manner. One rather striking point is that, except in an occasional appendix and except as they are required for the condensed statement of a physical law, mathematical equations do not occur. The reader of this volume will not be troubled by analytical difficulties. In this respect the articles in this volume offer a striking contrast to those on similar topics in the Encyclopædia Britannica.

All of the material contained in these articles can be found scattered through the earlier handbooks or the recent scientific periodicals. The criticism may therefore be made that this volume tells a physicist nothing with which he is not already acquainted, while it is of no value to one who is not a physicist, by reason of the fact that the latter would be unable to follow the condensed argument.
This criticism, however, is rather forced. Many physicists who have been carrying on intensive work in limited fields will find here a very acceptable summary of those portions of the subject with the literature of which they have not been able to keep in touch.

As the contributors of the articles in this volume are almost all Germans, it is natural that the work of German physicists should receive adequate, perhaps unduly favorable, recognition. Thus Helmholtz is given credit for originating the present electron theory through the emphasis he placed upon Faraday's statement concerning the absolute quantity of electricity associated with the particles or atoms of matter. Probably most physicists have come to the conclusion that Faraday stated for electrolysis in as clear language as it could be stated the law of multiple proportions of electricity and matter. ${ }^{1}$ Helmholtz had no more experimental evidence than had Faraday to extend this law beyond the field of electrolysis. It required the work of Schuster, Perrin, Kaufmann, Wilson, J. J. Thomson, to complete the statement. If we are going to give credit along this line to any one between Faraday and these later workers, we should not lose sight of the fact that in 1871 before the British Association, Johnstone Stoney spoke of the quantity of electricity appearing in electrolysis as the natural unit and later gave to it the name electron-a name which has been retained.

Ordinarily the writers of articles have not overstated the importance of their own contributions, but in the article on Wireless Telegraphy by Ferdinand Braun full justice is done to the author's experimental work.

Passing from electricity to thermodynamics one is surprised to see even in a minor paragraph the name of Holtzmann preceding that of Joule in connection with the determination of the mechanical equivalent of heat. We know that Holtzmann by his work on the specific heat of gases made a contribution of some importance and that he computed the mechanical equivalent of heat-but his ideas were hazy as to the nature of heat, for 1 See "Experimental Researches," Vol. I., par. 852. 
at times he assumed, as did Carnot, that the quantities of heat entering and leaving the cylinder of an engine, irrespective of the performance of work, were equal. If for the sake of completeness Holtzmann's work be referred to in this volume, so too should that of Marc Léguin (1839), who as far as the performance of an engine is concerned anticipated other workers (except possibly Rumford and Davy) in a partial statement of the law of the equivalence of heat and work.

Had this volume been written by American physicists, emphasis would have been placed on parts of the subject not here noticed. Wood on resonance spectra, Nichols and Merritt on fluorescence, Miller, Webster, Sabine on sound, Michelson on the rigidity of the earth, Pupin, G. W. Pearce on wireless telegraphy, would have been recorded.

But when we come to view the great body of philosophical thought which has come to us in this past generation we must give to Teutonic physicists credit for a large share. Boltzmann's conception of the entropy of a body in terms of the probability of state; the extension by Planck of the idea of entropy and temperature to radiation, leading to the distribution of energy in the spectrum of a full radiator and to the bewildering quantum theory; Einstein's contributions to molecular theory and to the theory of relativity-these stand out as substantial portions of "Die Kultur der Gegenwart."

G. F. Hull

\section{SPECIAL ARTICLES PEANUT MOSAIC}

ON September 28, 1915, while looking over a field in which peanuts (Arachis hypogcea) had been grown annually for the past six years a plant was observed, one shoot of which bore mottled leaves. A careful search of the entire field was made, but no other plant bearing mosaic leaves was found. This made the writer suspect that the trouble was not infectious. It seemed advisable to test this point further, especially since the mosaic plant was otherwise healthy except for a few leaf spots produced by Cercospora personata.

This mosaic plant was transferred to the greenhouse. Before final potting two of the mature pods were removed from the plant and opened, and four peas taken from them were planted at once in a pot of greenhouse soil. The four resulting plants together with two other seedlings which came up later from peas left on the mosaic plant, have been under observation during the past five months. In no case have any signs of mosaic developed. It would thus appear that this mosaic was not carried by the seed.

The transplanted mosaic plant continued to grow and produce new leaves at the ends of the shoots, but in no case did any but the mosaic shoot produce new mosaic leaves.

To obtain further data as to the infectious nature of this mosaic a pot of four peanut plants from a 1914 crop of seed was selected. Two plants were slashed near the ends of the shoots with a flamed scalpel to serve as checks. The other two plants were treated in a similar way, except that into the slashed stems bits of macerated mosaic leaflet were inserted. These plants have been under observation for the past five months but no signs of mosaic have developed on either the checks or inoculated plants.

On October 14, 1915, a pot containing peanut plants from the 1914 seed was taken to the laboratory. By means of India ink circular areas were marked on each leaflet of one plant. Within these circles the tissues were pierced several times with a flamed dissecting needle. This plant served as a check. The second plant in the same pot was treated in a similar way except that before piercing the leaf tissues the needle was moistened in the juice from mosaic leaflet freshly removed from the potted mosaic plant. Similar checks and inoculations were made on garden peas (Pisum spp.) growing in pots, using juice from the mosaic peanut leaflet. On November 13, 1915, the above plants were carefully examined, but neither the checks nor the inoculated plants showed any sign of mosaic on either young or old leaves.

On November 13, 1915, to further test the infectious nature of this peanut mosaic one check was prepared by injuring each leaflet of the plant by pinching it between the thumb 